\title{
Powerlessness: A Source of Evil
}

\section{Joseph E. McCormick}

Rollo May, in his book Power and Innocence (1972), argues that lack of power in people's lives is the breeding ground for violence. When people are powerless to effect change in what is perceived as a hopeless situation, the by-products are the destructive forces of bitterness, apathy, frustration, rage, and violence. The events leading to the infamous Kingston Penitentiary riot festered in a state of hopeless frustration for a lengthy period of time before the carnage. Both inmates and guards felt powerless to effectively influence their situation. Both sides were victims of the same social cancer: powerlessness.

To focus on the problem of powerlessness in the criminal justice system, the philosophy behind incarceration must be understood. Canada statistically has one of the highest rates of imprisonment in the western world. The ultimate aim of incarceration is fourfold: the punishment of offenders, the protection of society, the deterrence of crime, and to a lesser degree the rehabilitation of offenders. Recidivism rates approaching eighty percent (Parliamentary Subcommittee on Penitentiaries, 1977:35) clearly indicate that incarceration as a means of rehabilitation is ineffective. Indeed, incarceration of non-violent offenders is a grossly expensive waste of time, money and manpower. A significant body of correctional professionals have adopted the "nothing works" philosophy,* concluding that penal facilities serve only as warehouses. Such fatalism, while perhaps understandable, is yet another manifestation of powerlessness. It is time to concentrate on the central problem instead of being dominated by it.

Historically, the Canadian justice system is conservative by nature, built on the traditions and experience of British judiciary and penology. More recently it has adopted aspects of the American models. It must be recognized that modern society has abdicated responsibility for its social blemishes to institutional care. The burdens placed on our courts and penal institutions exist largely because we have turned correction of our prodigal sons and daughters over to a bureaucratic industry of baby-sitters. The term industry is not a misnomer for it encompasses police, judges, lawyers, clerks, guards, psychologists, and a host of other professionals who depend directly on the continuance of criminal deviance for their livelihoods.

Every year governments lament the costs of criminal justice. Yet, every year each segment of the industry applies for a larger slice of the budgetary

*This philosophy, as a recognized school of thought, evolved primarily out of a highly controversial study conducted by Martinson (Spring 1974) and has since been shown to be a flawed and defeatist attitude by Canadians (see Gendreau, 1981). 
pie. With all our advancement we remain a society that seems unable, or unwilling, to cope with its own deviance. Worse, the institutions designed to control and alleviate it may be inadvertently contributing to its very increase. Increased budgets for manpower by police, for example, produces a ripple effect that is felt throughout the industry. More police lay more charges, further taxing the courts, jails, and prisons. Politicians cry for tougher law enforcement in response to perceived need; media sensationalism of a few high profile cases cause emotional panic; the justice systembemoans the frustrations of a revolving door syndrome; the economic and social cost of a failing and self-perpetuating industry is appalling. The result is the frustration of powerlessness experienced at every level, while parliamentary study upon study produce few, if any, meaningful solutions.

The consensus is that the system does not work. Yet, the people who are most affected by it, offenders and correctional workers, are powerless to change the system for the better. Many good people come to work in corrections, well motivated to be effective, fair, and progressive, only to become disillusioned, frustrated, and apathetic. Likewise, offenders who had a genuine desire and the potential for effective rehabilitation leave embittered, resentful, and angry. Are the two sides diametrically opposed? I argue that in desired goals, often not. However, a cumbersome system that clings to a peculiar mixture of nineteenth century penchant for bars and twenty-first century promise of enlightened thinking robs both the offender and worker of the opportunity to achieve those goals. In short, rehabilitation and punishment are not compatible. Prisons warehouse the dangerous and punish the guilty. They are incapable of fostering rehabilitation and ought not to pretend otherwise.

Canada has modest reason to be proud of its alternatives to incarceration. Community service programs, fine options, and victim/offender reconciliation, while exceedingly worthwhile, are barely initial steps; mere band-aid approaches to a malignant cancer. None of these advances solves the more acute problems that daily affect the lives of the two groups striving to function behind prison walls. Two-thirds of those incarcerated pose no threat, other than that of being a nuisance to society. Overcrowding is a problem common to all penal facilities, no matter how rapidly built. Tensions produced by powerlessness are dramatically highlighted only after tragedy strikes. The suicide of a young woman in Winnipeg's Public Safety Building, the senseless slaughter of two living unit officers in Stoney Mountain Penitentiary, and murder upon murder in Millhaven Institution bring fleeting attention to bear on the symptoms. 
Ignored are inmates who lose their sanity in solitary confinement; physical and emotional violence; slavery to drugs and homosexuality; an unwieldy bureaucracy that frustrates workers equally as much as inmates; staggering illiteracy rates; lack of meaningful programs; the loss of basic human dignity. When the symptoms of powerlessness manifest themselves in the extreme, an apathetic society shrugs its shoulders and attributes the blame to faulty administration. The symptoms are usually misinterpreted as the fundamental problem.

For the inmate, powerlessness to change the dehumanizing aspects of incarceration (alienation from family and community, boredom, loss of individuality, surrender of decision making, absence of meaningful reconciliation) is a threat to his/her existence. If the inmate capitulates to the system, he/she is in danger of becoming a non-person and institutionalized, while expression of individuality can result in being labelled as incorrigible. For the correction worker, powerlessness to be able to effect meaning in their profession and lack of goal attainment and career satisfaction lead to apathy and acquiescence to the "rut system". The system subjects the average worker to a mindless routine of key turning and inmate counting and bureaucratic processes.

Powerlessness to change effectively a hopeless situation causes people to think and behave irrationally. When despair replaces hope, the potential for cruelty exists. Game playing and manipulation of people for power advantage becomes an exercise that turns well intentioned people against one another: inmates against guards, guards against guards, inmates against inmates.

Correctional workers complain of the lack of discipline, administrative inconsistency, the absence of respect for authority, and constant tension. They are forced to endure the childish behavior from adults and live with the continual risk of danger. Inmates complain of harassment by vindictive guards, lack of communication, staff incompetency, overcrowding, and lack of privacy for the most basic of human needs. Both sides grow bitter and become estranged actors in a tragic comedy.

The irony of so-called rehabilitation is that it promotes the very behavior it should be discouraging. Both sides resort to game playing, out of frustration. Inmates feel compelled to lie and manipulate to gain limited access to parole oriented programs. Staff use acceptance or denial as a lever to place pressure on inmates for information. The stick and carrot approach is brutal psychological warfare, carried out in the vilest of trenches. The power struggle, thus, uses the best of systems for the worst of intentions. 
The growing problem of recidivism can be viewed as a polarization of those unable or unwilling to cope with life in the real world. "Doing time" is easier than struggling to survive in a world with which ex-offenders are ill-equipped to deal, and from which they outcast. Not only are offenders being released without adequate resolution of anti-social and criminal behaviors, but they are often in worse psychological and spiritual condition than when they entered. Prison shelters offenders from life's realities, teaches them to cope by manipulation and coercion, and fails to foster responsibility. Indeed, incarceration in its present form is the antithesis of rehabilitation.

Inmates quickly lose hope of achieving any problem solving counselling, or redirectional goal setting, because the system cannot economically provide qualified staff or adequate facilities. It is common for those with dire psychological needs to be told that they are doing too much time to deserve treatment, and to re-apply in a few years. Yet, while meaningful programs are denied, the unctuous rhetoric of Corrections Canada's "Mission Statements" gives the perception of an advanced medical model in our penal institutions.

Alarmingly, the objectives of professional staff and those charged with security responsibilities often clash. It is no secret that the ratio of budget appropriation for security is approximately 500 percent (Wortherspoon, 1986) greater than that of education and vocational training. This budget imbalance is further reflected in the poor working relationship between the two bodies of staff. Security dominates all aspects of prison life and is not hesitant about reinforcing its authority, whether justified or not.

While frustrated by the lack and the quality of programs, inmates witness daily a litany of budgetary wastes and bureaucratic ineffectiveness. The private sector would shudder at the mismanagement and lack of financial accountability. A school office may be denied a badly needed typewriter, while a million dollar electronic locking system, which saves the guards' necessity of manually turning keys, is readily justifiable. Such gross inconsistencies amplify the necessity for separating rehabilitation from incarceration. Powerlessness to effect programming condemns both sides to do "dead time". The inmate completes his/her sentence in a vacuum, learning only those skills that reinforce deviant behavior and entrench cunning attitudes. The correctional worker discovers that he/she is only a baby-sitter stuck in the rut system awaiting pension.

Like a marriage gone sour years ago, the adversaries now focus only on the symptoms and their distrust and resentment of each 
other. The problem of powerlessness is lost in an obscure maze of disillusionment. Thus, prisons become factories of hate.

The correctional dilemma will not be cured by band-aid approaches. The cancer of antisocial behavior exists in spite of all efforts. Building more prisons or expanding the size of the industry is not an answer, although it may have temporary political advantages. Powerlessness is a condition of the human experience that has its roots in social structure, not just prison. If an offender cannot find dignity and self-respect in his/her community, he/she is certain not to develop them in prison. The cancer of powerlessness will only be conquered with recognition of its evil pervasiveness. An holistic society is one that develops a consciousness for healing. Canada needs to focus on the roots of powerlessness as a determinant of criminal behavior. Poverty, social injustice, illiteracy, devaluation of the disadvantaged and our indigenous peoples ought to be attacked far more enthusiastically than the individual wrong-doer. We are a society with a bully's school-yard mentally of picking on, condemning, and ostracizing the weak and insignificant.

It is time to recognize the criminal justice system for its true raison d'etre - that is a system for extracting vengeance. Rehabilitation can only take place in an environment that fosters positive change in the human heart. That seldom happens in prison.

\section{REFERENCES}

Gendreau, P. 'Treatment in Corrections: Martinson Was Wrong!" Canadian Psychology 22:4, 332-337

Government of Canada (1977) Parliamentary Sub-Committee on Penitentiaries. Ottawa: Queen's Printer.

Martinson, R. (Spring 1974) "What Works: Questions and Answers About Prison Reform.' Public Interest 34, 22-54.

May, R. Power and Innocence: A Search for the Source of Violence. New York: Norton.

Wortherspoon, T. (1986) 'Prison Education and Fiscal Crisis.' In B.D. MacLean (Ed.) The Political Economy of Crime. Scarborough: Prentice-Hall Canada, Inc. 
